\title{
APO EM EDIFICAÇÃO PÚBLICA ESCOLAR: CASO DA E. M. LUIZA T. DE ANDRADE- RJ
}

\author{
SILVA, Juliana \\ UNILASALLE-RJ, e-mail: juliana_christiny@hotmail.com \\ BRASIL, Paula \\ UEZO e UNILASALLE-RJ, e-mail: paula.brasil@lasalle.org.br
}

\begin{abstract}
RESUMO
A presente análise consiste na avaliação pós-ocupação (APO) da Escola Municipal Luiza Terra de Andrade, localizada em São Pedro da Aldeia, RJ. Este estudo possui o objetivo de compreender o cenário contemporâneo da arquitetura escolar pública brasileira. A relevância desta pesquisa baseia-se sobre o fato de que a edificação escolar influencia diretamente o desempenho dos alunos, professores e colaboradores no processo de ensino- aprendizagem. A respectiva avaliação pós-ocupação procura compreender de forma aprofundada as necessidades de todos os grupos de usuários desta edificação de ensino. A partir dos diagnósticos realizados, no ambiente construído, estruturou-se uma relação de aspectos necessários para a execução de projetos de edifícios escolares. Assim, a escola analisada retrata a maneira como a educação básica no Brasil tem sido desenvolvida. A inadequação qualitativa e quantitativa dos ambientes retrata a realidade de inúmeras escolas existentes em todo o território nacional. Deste modo, torna-se emergencial mudar a maneira de se projetar escolas e tornar o usuário o centro de todo o processo de projeto.
\end{abstract}

Palavras-chave: Avaliação Pós-Ocupação, Ambiente Construído, Arquitetura Escolar, Diretrizes Projetuais.

\begin{abstract}
The present analysis consists of the post-occupation evaluation (APO) of the Luiza Terra de Andrade Municipal School, located in São Pedro da Aldeia, RJ. This study aims to understand the contemporary scenario of Brazilian public school architecture. The relevance of this research is based on the fact that school building directly influences the performance of students, teachers and collaborators in the teaching-learning process. The respective post-occupation evaluation seeks to understand in depth the needs of all groups of users of this educational building. From the diagnoses carried out, in the built environment, a list of necessary aspects for the execution of projects of school buildings was structured. Thus, the school analyzed portrays the way in which basic education in Brazil has been developed. The qualitative and quantitative inadequacy of the environments portrays the reality of numerous schools throughout the country. In this way, it becomes urgent to change the way schools are designed and to make the user the center of the entire design process.
\end{abstract}

Keywords: Post-occupation Evaluation, Built Environment, School Architecture, Design Guidelines.

SILVA, J.; BRASIL, P. APO em edificação pública escolar: caso da E. M. Luiza T. de Andrade - RJ. In: SIMPÓSIO BRASILEIRO DE QUALIDADE DO PROJETO NO AMBIENTE CONSTRUÍDO, 6., 2019, Uberlândia. Anais... Uberlândia: PPGAU/FAUeD/UFU, 2019. p. 998-1013. DOI https://doi.org/10.14393/sbqp19092. 


\title{
1 INTRODUÇÃO
}

A arquitetura escolar é complexa, pois a mesma deve atender as necessidades de todos os seus usuários garantindo a eficiência dos lugares destinados as diversas práticas educacionais.

\begin{abstract}
A formação educacional de um indivíduo está relacionada com uma rede complexa de fatores sociais, econômicos, pedagógicos e ambientais. A configuração física do ambiente escolar e a adaptação do estudante a este meio exercem grande predominância na evolução do aprendizado. O edifício escolar deve obedecer às normas e, principalmente, oferecer segurança, acessibilidade e conforto aos seus usuários. Tais condições de conforto no ambiente afetam diretamente os usuários tanto no aspecto fisiológico como psicológico e consequentemente no desempenho das atividades (GRAÇA, 2002).
\end{abstract}

Esta pesquisa, realizada em outubro de 2018, analisa a E. M. Luiza Terra de Andrade, localizada em São Pedro da Aldeia-RJ, que se porta como um retrato do cenário atual das escolas públicas brasileiras que em sua maioria possuem projetos arquitetônicos inadequados à prática do ensino-aprendizagem.

Desta maneira, a avaliação pós-ocupação (APO) da referida instituição visa contribuir para o meio acadêmico levantando questionamentos sobres as diretrizes atualmente utilizadas no Brasil para elaboração de arquitetura educacional, a fim, de aprimora-las auxiliando assim o projetar do arquiteto.

\section{ESCOLA LUIZA TERRA DE ANDRADE}

\subsection{Localização}

Localizada na Região da Costa do Sol a cidade de São Pedro da Aldeia está inserida na mesorregião das Baixadas Litorâneas do Rio de Janeiro e na microrregião Lagos. (MOREIRA; AZEVEDO, 2012). Segundo IBGE (2010), a população estimada para o ano de 2018 é de 102.846 mil pessoas. O município, encontra-se cercado pelas cidades de Araruama, Iguaba Grande, Cabo Frio e a Laguna de Araruama.

São Pedro da Aldeia

Laguna de Araruama

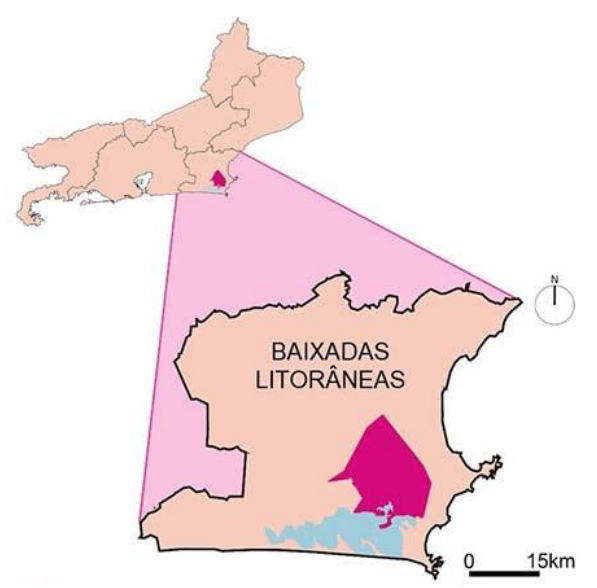

Figura 1 - Mapa do Rio de Janeiro, mesorregião das Baixadas Litorâneas Fonte: Elaborado pelas autoras (2019)

A Escola, alvo desta pesquisa, está localizado na Rua Luiza Terra da Andrade, $s / n^{\circ}$, no Bairro Campo Redondo no município de São Pedro da Aldeia - RJ. Tem 
como mantenedora a Prefeitura Municipal de São Pedro da Aldeia (MOREIRA; AZEVEDO, 2012).

\subsection{Histórico}

A Escola Municipal Luiza Terra de Andrade foi fundada no dia 16/10/1986 registrada sobre o Decreto $n^{\circ} 262$ de 16/10/1986 da Prefeitura Municipal de São Pedro da Aldeia. A escola recebeu este nome em homenagem à senhora Luiza Terra de Andrade que gentilmente doou o terreno para a construção da escola em decorrência da inexistência de uma Unidade Escolar no bairro (MOREIRA; AZEVEDO, 2012).

A referida unidade escolar foi a primeira escola construída no bairro Campo Redondo e encontra-se em atividade até a contemporaneidade. Atualmente é a única no bairro a atender aos alunos do $6^{\circ}$ ao $9^{\circ}$ ano do Ensino Fundamental e Educação de Jovens e Adultos (EJA), que são oriundos dos bairros: Campo Redondo, Colina e São João (ANDRADE, 2016). Além dela existe no referido bairro somente a Escola Municipalizada Manoel Moraes da Silva que é responsável por anteder os alunos da Educação Infantil e ensino fundamental do $1^{\circ}-5^{\circ}$ ano.

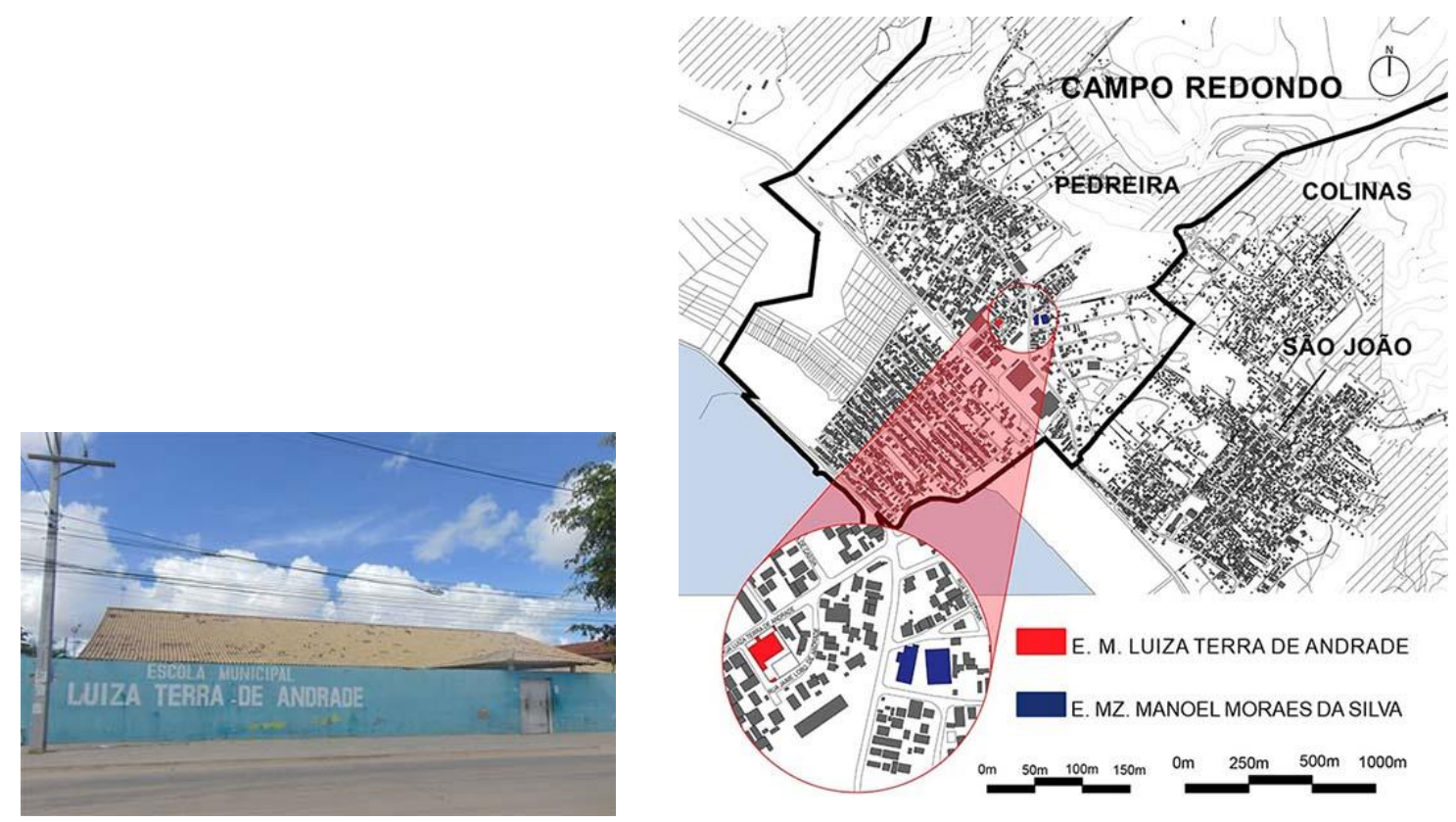

Figura 2 - Escolas Públicas do Bairro Campo Redondo e a fachada principal da E. M. Luiza Terra de Andrade -

Fonte: Elaborado pelas autoras a partir da Base Cadastral de São Pedro da Aldeia

\subsection{Síntese do Projeto Político Pedagógico Integração e Socialização: Escola- Comunidade}

Atualmente o maior desafio na execução de projetos de arquitetura escolar é a articulação do projeto arquitetônico com o projeto político pedagógico (PPP). Compreender o PPP é essencial para a concepção de projetos de edifícios educacionais que atendam aos seus princípios pedagógicos, suas propostas curriculares e seus usuários.

O PPP da Escola Luiza Terra de Andrade é baseado nos princípios do Interacionismo, defendendo a Pedagogia Progressista. Como Paulo Freire, 
propõem-se um movimento transformador e critico que considera o homem como um sujeito histórico. Uma pedagogia moderna e humana que permite a integração entre todos que participam do processo ensino-aprendizagem, a vida, a autonomia intelectual, a ecologia, a interação entre professores e alunos e que promova a construção do conhecimento (ANDRADE, 2016).

\begin{abstract}
A visão interacionista entre o trinômio indivíduo, ambiente construído e ambiente natural deve priorizar a proteção do meio-ambiente desperta uma consciência ecológica que irá influenciar no processo educativo, incluindo não só a reflexão sobre o papel que a criança desempenha enquanto cidadão em formação - sua educação ambiental que inclui sua relação com o ambiente natural e construído - mas também a compreensão de que a própria edificação escolar deve também interagir e se harmonizar com esse ambiente (AZEVEDO, 2002).
\end{abstract}

Deste modo, fica claro que os princípios norteadores e os objetivos existentes no PPP da E. M. Luiza T. de Andrade possuem como eixo central a formação do aluno.

\title{
3 AVALIAÇÃO PÓS- OCUPAÇÃO DA ESCOLA MUNICIPAL LUIZA TERRA DE ANDRADE
}

A avaliação pós- ocupação (APO) é um processo rigoroso e sistemático de avaliação de um edifício já construído e após um determinado período de tempo de sua ocupação. A APO possui como alvo os usuários da edificação e suas necessidades. A partir das análises realizadas durante a avaliação é possível compreender as decisões tomadas no decorrer da execução do projeto. Assim, é possível assimilar o desempenho atual do edifício, seus desdobramentos e consequências sobre os usuários. Este conhecimento forma uma base sólida para a concepção de futuros edifícios (PREISER, 1988).

A metodologia da pesquisa contempla a avaliação pós- ocupação da Escola Municipal Luiza Terra de Andrade, que está organizada nos topicos: 1- Mapa Comportamental; 2- Poema dos Desejos; 3- Walkthrougt; 4- Questionários; 5Avaliação Técnica; 6- Matriz de descobertas/ Diretrizes para futuros projetos.

\subsection{Mapa Comportamental}

O mapa comportamental é uma ferramenta utilizada para registrar 0 comportamento e as atividades dos usuários em um determinado ambiente. A partir do mesmo é possível identificar os usos, os arranjos espaciais ou layouts, os fluxos e as relações espaciais. Pode-se ainda, indicar graficamente as interações, os movimentos e a distribuição das pessoas relacionando o espaço e o tempo que elas permanecem no ambiente estudado (RHEINGANTZ et al., 2009).

O Mapa Comportamental da referida Escola registrou as atividades e a localização dos alunos no horário do recreio, por meio de mapa esquemático, ilustrando o lugar e o tempo de permanência dos educandos no mesmo. Verificou ainda a adequação do ambiente construído as necessidades de seus usuários. 


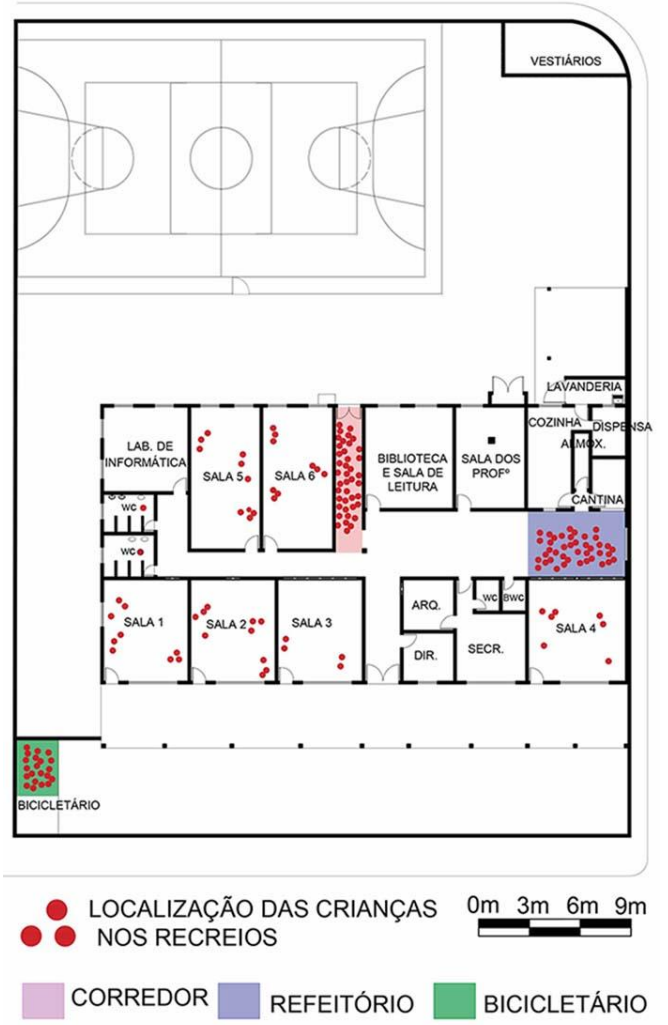

Figura 3 - Mapa Comportamental Fonte: Elaborado pelas autoras (2019)

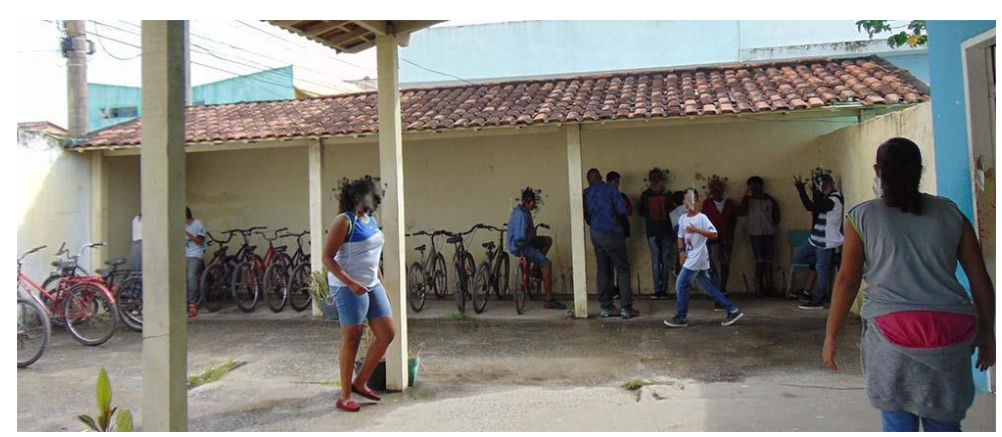

Figura 4 - Mapa Comportamental Fonte: Elaborado pelas autoras (2019)

Assim, destaca-se que a escola não possui área de convívio e socialização adequada para os educandos. As crianças ficam em pé no bicicletário, sentam no chão do corredor interno ou no refeitório. Este fato demonstra uma característica hostil da arquitetura da escola em estudo. Uma arquitetura que não propicia o desenvolvimento das relações humanas e sociais.

\subsection{Poema dos desejos}

Wish Poems ou Poema dos Desejos é um método que encoraja os usuários a refletirem e descreverem espontaneamente o ambiente de seus sonhos (SANOFF, 2001). É um instrumento de pesquisa no qual os usuários de um determinado ambiente expressam através de sentenças escritas ou de desenhos suas necessidades e desejos em relação ao ambiente construído no qual pratica atividades. Destaca-se ainda que este método impulsiona a estruturação de projetos arquitetônicos participativos, pois reconhece os usuários e suas necessidades (RHEINGANTZ et al., 2009). 
No Poema dos Desejos, da Escola municipal Luiza Terra de Andrade, os alunos escreveram um pequeno texto narrando os pontos positivos e negativos do edifício escolar, apontaram suas necessidades, seus desejos e sonhos referentes ao edifício educacional. A partir do recurso do desenho foi proposto que os alunos realizassem dois desenhos. O primeiro desenho é intitulado: a escola de hoje e o segundo é intitulado: a escola que queremos. A figura 5 é um exemplar dos desenhos propostos e a figura 6 é um exemplar do texto, ambos desenvolvidos por alunos.

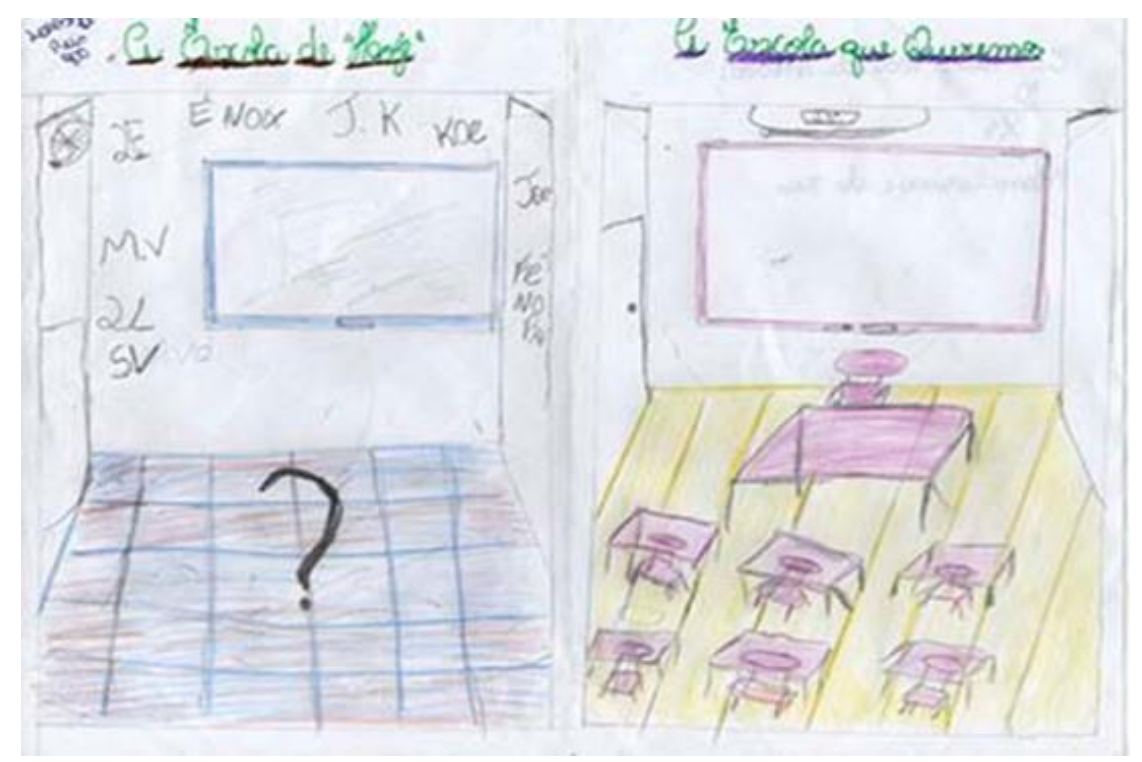

Figura 5 - Desenho de uma aluna da turma 900 -

Fonte: Arquivo das autoras (2018)

\begin{tabular}{|c|}
\hline Q iscala que times \\
\hline 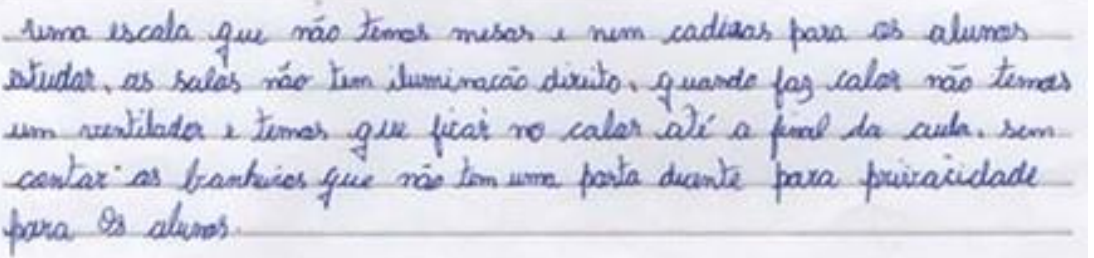 \\
\hline a scala que quesmes \\
\hline 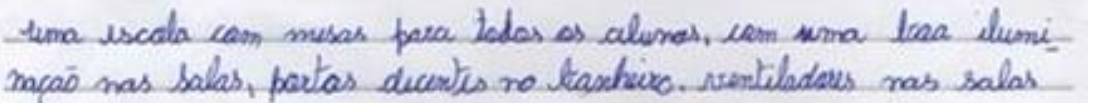 \\
\hline
\end{tabular}

Figura 6 - Poema de uma aluna da turma 800 -

Fonte: Arquivo das autoras (2018)

A partir dos desenhos e poemas desenvolvidos ficam claros os anseios e necessidades dos educandos frente aos seus ambientes de ensino. Note-se que os pedidos realizados fazem a referência a elementos básicos de ensino como: mobiliário, material escolar, higiene nos ambientes. 


\subsection{Walkthrough}

A análise walkthrough articular observações de técnicos com entrevistas dos usuários de determinado equipamento arquitetônico, avalia o desempenho do ambiente construído e identifica de maneira descritiva dos aspectos negativos e positivos dos ambientes analisados. Para executar as análises pode-se utilizar técnicas de registro, como por exemplo, mapas, plantas, checklists, gravações de áudio e de vídeo, fotografias, desenhos, diários, fichas, etc (RHEINGANTZ et al., 2009).

\section{Quadro 2 - Ficha de Registro da Análise walkthrough}

\begin{tabular}{|l|l|}
\hline Ambiente: Sala de Aula 1 & Data: 12/12/2018 \\
\hline Ocupantes: Crianças de 11- 12 anos & Área Aproximada: $30 \mathrm{~m}^{2}$ \\
\hline Atividades: Ambiente de ensino- aprendizagem & Pé Direito: $2.60 \mathrm{~m}$ \\
\hline $\begin{array}{l}\text { Mobiliário: A quantidade de mesas e carteiras existentes na sala não atente a quantidade de } \\
\text { alunos que utilizam o ambiente e o mobiliário existente encontra-se em péssimas condições de }\end{array}$
\end{tabular}
uso.

Materiais: Piso cerâmico branco pontilhado de preto, alvenaria com acabamento de pintura branca, laje de concreto e portas e janelas para a varanda.

Temperatura: Prejudicada pela irradiação direta do sol na janela lateral, pela falta de ventilador e pela falta de ar condicionado. O calor insuportável interfere diretamente no desempenho dos alunos e professores.

Iluminação: Possui iluminação natural, porém a irradiação direta do sol em parte das carteiras, mesas e no quadro é prejudicial.

Ventilação: Possui ventilação direta, porém não eficiente. A ausência de ventilador e ar condicionado deixa o ambiente extremamente quente.

Ruído: É prejudicado quando existem alunos no pátio, por conta das janelas que estão com os vidros quebrados, e pela existência de cobogós direcionados para um corredor interno.

Comentários: Segundo os alunos a falta de mobiliário torna necessário que dois ou três alunos tenham que dividir a mesma mesa. A falta de ventilação adequada torna o ensinoaprendizagem desconfortável. E a iluminação e ruído inadequado afetam a visão e a atenção na aula.

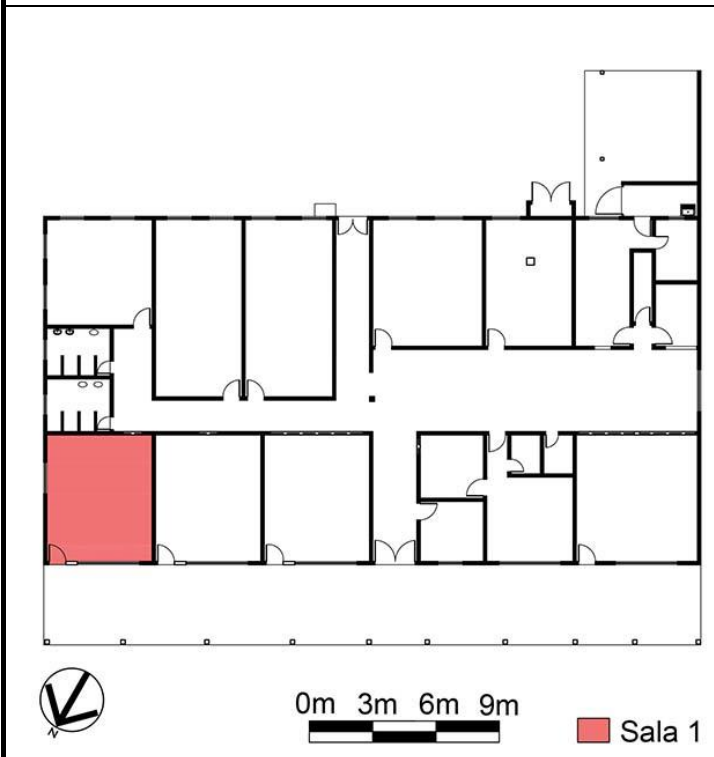

Planta da E. M. Luiza T. de Andrade com destaque na sala 1

Fonte: Elaborado pelas autoras (2019)

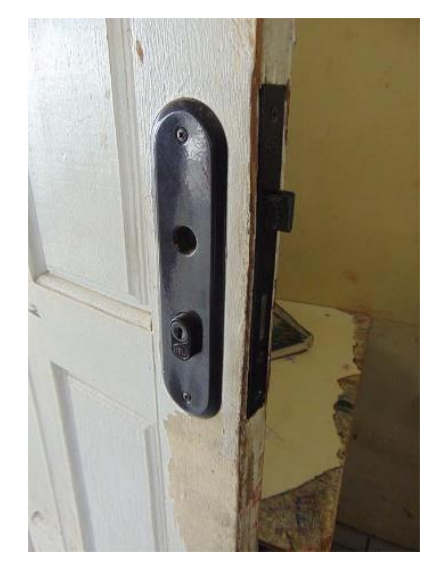

Fechadura da Porta Quebrada e detalhe do Mobiliário em mau estado

Fonte: Arquivo das autoras (2018) 


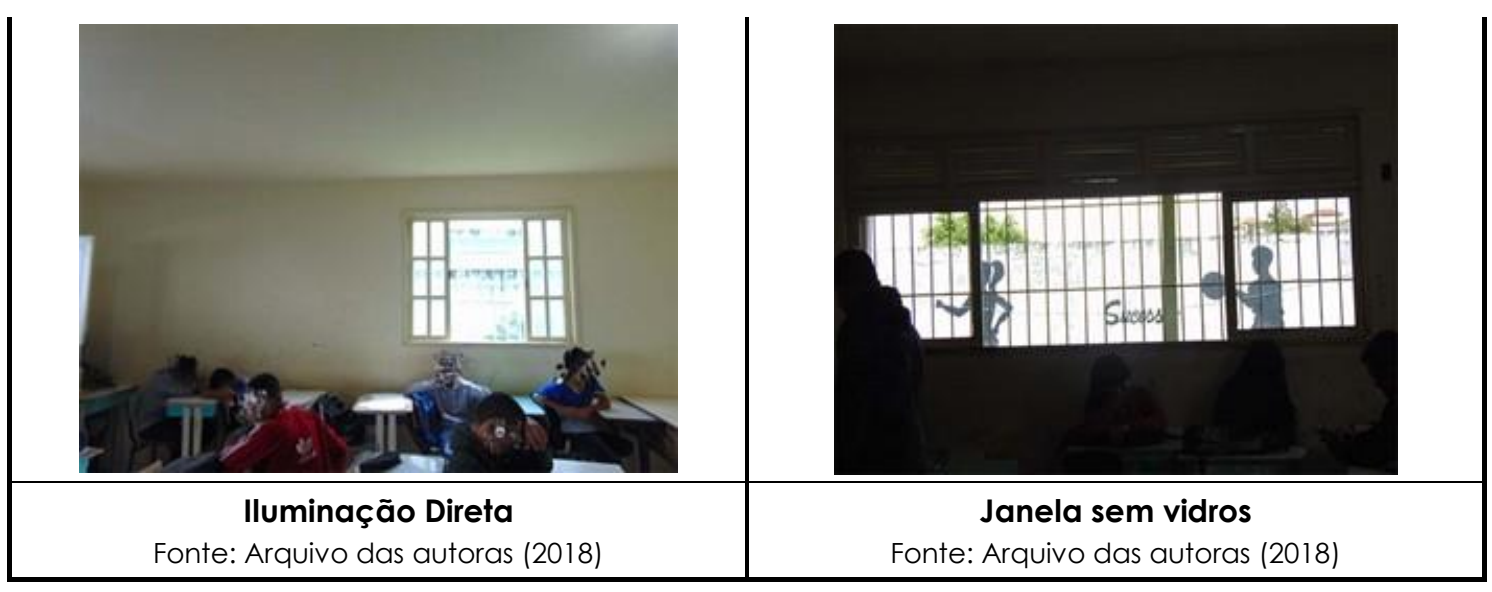

Fonte: Elaborado pelas autoras

A análise walkthrough da Escola municipal Luiza Terra de Andrade foi realizada em todos os ambientes/cômodos existentes na unidade escolar articulando registro iconográficos e entrevistas informais com os usuários dos respetivos ambientes.

Acima apresenta-se um exemplar da ficha técnica da análise walkthrough de uma das salas existentes na escola.

A sala de aula acima analisada possui características similares com as demais salas existentes na escola. Assim, destacam-se que: mobiliários deteriorados; ambientes não humanizados; salas de aula com iluminação e ventilação insuficiente e necessidade de tratamento acústico, influenciam diretamente a qualidade do ensino- aprendizagem da escola. Foi observado também que os espaços não são adaptados para portadores de necessidades especiais (PNE).

\subsection{Questionários}

O questionário é uma ferramenta de pesquisa que contempla perguntas referentes a uma determinada temática ou problema. É um instrumento frequentemente utilizado nas avaliações de desempenho, pois possibilita descobrir regularidades entre o grupo de usuários envolvido na pesquisa (RHEINGANTZ et al., 2009).

Durante a APO da Escola municipal Luiza Terra de Andrade foram aplicados cinco tipos de questionários que foram concebidos e direcionados de acordo com os diferentes grupos de usuários existentes na então unidade educacional. Um questionário foi direcionado a direção da escola, outro questionário aos professores, outro questionário aos demais funcionários, outro questionário aos educandos e outro aos responsáveis de cada aluno.

Quadro 3 - Funcionários e alunos que participaram dos questionários

\begin{tabular}{|c|c|c|}
\hline Administrativo & $N^{\circ}$ de Funcionários & $\begin{array}{c}\text { No de Funcionários que } \\
\text { participaram }\end{array}$ \\
\hline Diretor Geral & 01 & 01 \\
\hline Diretor Adjunto & 01 & 01 \\
\hline Assistente Administrativo & 02 & 01 \\
\hline Coordenador de Turno & 02 & 01 \\
\hline Auxiliar de Gestão & 01 & 00 \\
\hline
\end{tabular}




\begin{tabular}{|c|c|c|}
\hline Pedagógico & $N^{\circ}$ de Funcionários & $\begin{array}{c}N^{\circ} \text { de Funcionários que } \\
\text { participaram }\end{array}$ \\
\hline Professores & 42 & 28 \\
\hline Professores adaptados & 03 & 00 \\
\hline Serviço & $N^{\circ}$ de Funcionários & $\begin{array}{c}N^{\circ} \text { de Funcionários que } \\
\text { participaram }\end{array}$ \\
\hline Merendeiras & 04 & 03 \\
\hline Vigias & 03 & 01 \\
\hline Porteiro & 02 & 01 \\
\hline Alunos & $N^{\circ}$ de Alunos & $\begin{array}{c}N^{\circ} \text { de Alunos que } \\
\text { participaram }\end{array}$ \\
\hline $\begin{array}{c}6^{\circ} \text { ao } 9^{\circ} \text { ano Ensino Regular } \\
\text { e EJA }\end{array}$ & 312 & 216 \\
\hline
\end{tabular}

Fonte: Elaborado pelas autoras

Destacam-se a seguir fragmentos de cada tipo de questionário já respondido por seus respectivos grupos de usuários.

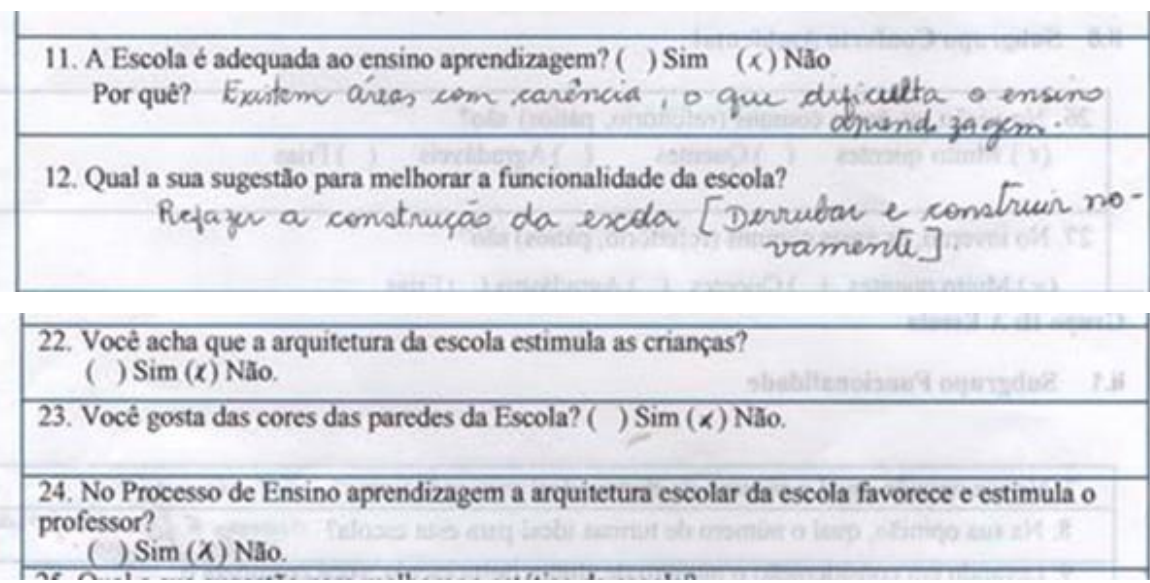

\begin{tabular}{l} 
47. O tamanho do seu espaço de trabatho e adequado para atender ao número de pessoas que \\
permanecem nele? $($ ) Sim $(X)$ Nåo \\
\hline 48. O mobiliário disponivel é adequado/suficiente para atender os alunos? ( ) Sim $(X)$ Não \\
\hline 49. O mobiliário disponivel é adequado/suficiente para atender os adultos? ( ) Sim $(X)$ Nào
\end{tabular}

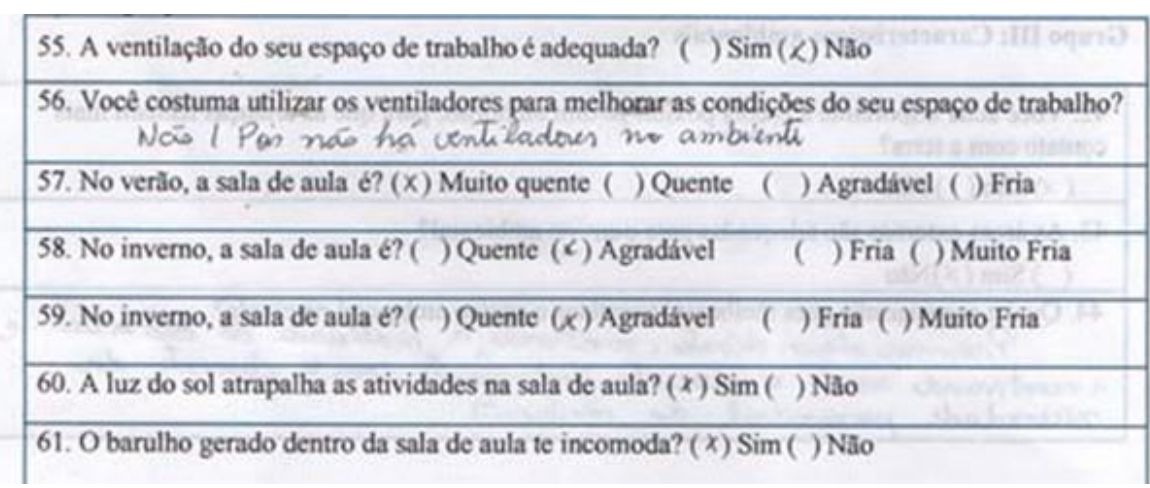

Figura 7 - Partes do questionário realizado com os professores. Exemplar respondido por uma professora-

Fonte: Arquivo das autoras (2018) 
6. Qual te o lugar da escola em que você mais gosta de ficar (mais legal)? Por qué?

Quadra posio la es alunes be divertem.

7. Qual o lugar da escola em que vocè menos gosta de ficar?

$$
\text { na rala. (mäo pela aula, mais pelo ecdor, ete.) }
$$

8. Qual o lugar da escola você acha mais bonito?

$$
\text { Diblidica }
$$

9. Qual o lugar da escola você acha mais feio?

$$
\text { Quadra }
$$

10. Vocé gostaria que a escola tivesse um jardim ou horta para vocé cuidar?

$$
\text { Im fardion pelia moncitro. }
$$

11. Como voge gostaria que fosse no pátio?

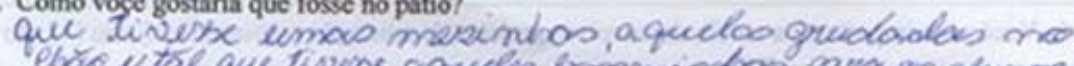

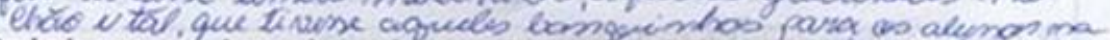

12. Qual o lugar que voce gostaria que tivesse aqui na escola e ainda nlo tem? hella do recrico

$$
\text { pala de informática. rentas remuso }
$$

13. Vocé tem alguma ideia para deixar a sala de aula mais legal $\mathrm{e}$ mais bonita? repager o pirso, e pecixor as jonelas

14. Vocêt tem alguma ideia para deixar a escola mais legal e mais bonita?

$$
\text { rulormar a exola tada }
$$

Figura 8 - Parte do questionário realizado com os alunos. Exemplar respondido por uma aluna da turma 802 -

Fonte: Arquivo das autoras (2018)

9. Qual a sua opinião sobre o banheiro dos funcionários? ( ) Excelente ( ) Bom ( ) Regular ( ) Ruim W Pessima

10. Qual a sua opinião sobre o banheiro dos alunos? ( ) Excelente ( ) Bom () Regular ( ) Ruim A Péssima

\begin{tabular}{l}
\hline $\begin{array}{l}\text { 16. Você acha que a arquitetura da escola estimula as crianças? } \\
\text { ( ) Sim Nåo. }\end{array}$ \\
\hline 17. Você gosta das cores das paredes da Escola? ( ) Sim Lâ.
\end{tabular}

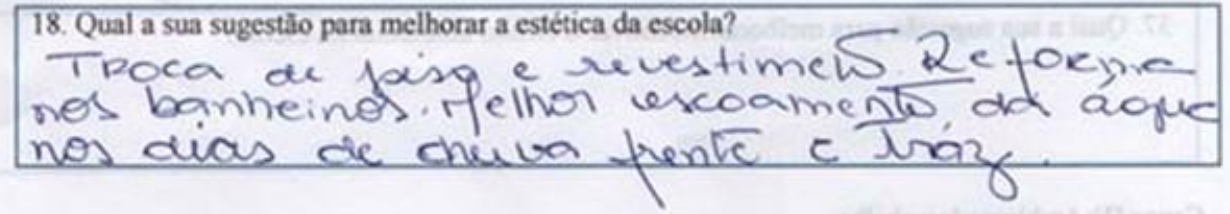

II.5 Subgrupo Conforto Ambiental

19. No verăo, as áreas comuns (refeitónio, pátios) săo? $\begin{array}{lll}\bigotimes \text { Muito quentes ( ) Quentes ( ) Agradáveis } & \end{array}$

20. No inverno, as áreas comuns (refeitório, pátios) salo?

( ) Muito quentes ( ) Quentes ( ) Agradáveis $($ Frias

21. Como ć a ventilaçăo das áreas comuns (refeitório, pátios)? Bom ( ) Regular (Xuim ( ) Péssima

34. A escola é adequada para receber crianças com necessidades especiais? ( ) Sim $\searrow$ Não

Figura 9 - Partes do questionário realizado com os demais funcionários. Exemplar respondido por uma servente -

Fonte: Arquivo das autoras (2018) 


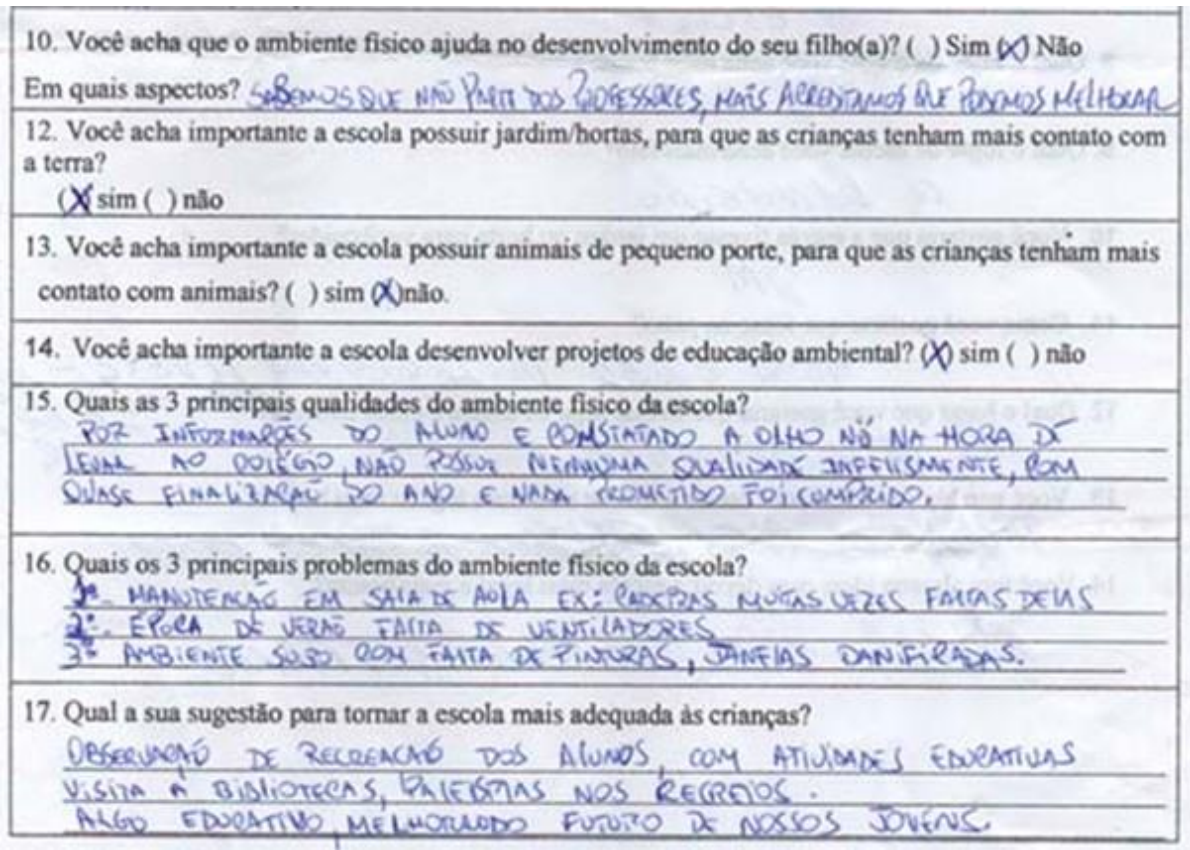

Figura 10 - Partes do Questionário realizado com os pais e responsáveis. Exemplar respondido por uma responsável (folha 1 de 1) -

Fonte: Arquivo das autoras (2018)

Ao analisar todos os questionários respondidos averígua-se uma coesão nas respostas marcadas e nas escritas pelos respectivos usuários. Verifica-se um consenso nas respostas que descrevem o anseio da realização de um novo projeto arquitetônico para a escola, pois a mesma não supre as necessidades qualitativas e quantitativas existentes.

\subsection{Avaliação Técnica}

A avaliação técnica do ambiente construído consiste em uma análise realizada por um especialista da área de arquitetura que examina a edificação observando as questões construtivas e funcionais da edificação.

Quadro 4 - Ficha Técnica

\begin{tabular}{|l|}
\hline Área do Terreno: $1733 \mathrm{~m}^{2}$ \\
\hline Área Construída total: $706 \mathrm{~m}^{2}$ \\
\hline Números de Pavimentos: Possui somente o térreo. \\
\hline \multicolumn{1}{|c|}{ Sistema Construtivo } \\
\hline Pilares e Vigas: Concreto armado \\
\hline Lajes: Concreto armado \\
\hline Paredes: Alvenaria \\
\hline Proteção para controle solar: Não possui \\
\hline Esquadria: De madeira e alumínio \\
\hline $\begin{array}{l}\text { Paramento- pisos: A maioria das salas com piso de ardósia e algumas salas com piso de } \\
\text { cerâmica branca pontilhada. Banheiros com cerâmica cinza escuro e branca. }\end{array}$ \\
\hline Acabamento- paredes: Pintura tinta cor creme e azulejos brancos. \\
\hline Cobertura: Telhado colonial. \\
\hline
\end{tabular}


Quadro 5 - Avalição técnica baseado nos requisitos das normas ISO 6241 e NBR 5674

\begin{tabular}{|c|c|c|c|}
\hline \multicolumn{4}{|c|}{ Escola - Todos os setores } \\
\hline \multicolumn{4}{|c|}{ Requisitos quanto ao desempenho: ISO 6241} \\
\hline REQUISITO & DEFICIÊNCIA & CONFORMIDADE & $\begin{array}{l}\text { OBSERVAÇÕES E } \\
\text { DESCRIÇÕES DOS } \\
\text { USUÁRIOS }\end{array}$ \\
\hline Estabilidade & - Beiral do Telhado em mau estado. & - & $\begin{array}{l}\text { - O Beiral do telhado } \\
\text { apresenta perigo de } \\
\text { cair nos usuários. }\end{array}$ \\
\hline $\begin{array}{l}\text { Segurança } \\
\text { contra fogo }\end{array}$ & $\begin{array}{l}\text { - Extintores não são suficientes para } \\
\text { atender a escola. } \\
\text {-Inexistência de equipes treinadas } \\
\text { para emergências. } \\
\text { - Rotas de fugas desqualificadas. } \\
\text { - Falta de alarmes e detectores de } \\
\text { fumaça. }\end{array}$ & - & $\begin{array}{l}\text { - É necessário } \\
\text { adequar-se as } \\
\text { normas de incêndio } \\
\text { e treinar o corpo } \\
\text { docente e discente } \\
\text { para emergências. }\end{array}$ \\
\hline $\begin{array}{l}\text { Segurança } \\
\text { ao uso }\end{array}$ & $\begin{array}{l}\text { O estado do acabamento do piso } \\
\text { de algumas salas está danificado } \\
\text { podendo causar acidentes. }\end{array}$ & - & $\begin{array}{l}\text { - É necessário a } \\
\text { existência de pisos } \\
\text { adequados com } \\
\text { objetivo de evitar } \\
\text { acidentes escolares. }\end{array}$ \\
\hline $\begin{array}{l}\text { Conforto } \\
\text { visual e tátil }\end{array}$ & $\begin{array}{l}\text {-Falta de Sinalização nos pisos e } \\
\text { marcadores com escrita em braille }\end{array}$ & - & $\begin{array}{l}\text { - O conforto visual e } \\
\text { tátil é essencial para } \\
\text { garantir a inclusão } \\
\text { social. }\end{array}$ \\
\hline $\begin{array}{l}\text { Conforto } \\
\text { acústico }\end{array}$ & $\begin{array}{l}\text { - O cobogó existente em duas salas } \\
\text { permite a que o som externo das } \\
\text { salas adentre o ambiente. }\end{array}$ & - & $\begin{array}{l}\text { - Atrapalha que os } \\
\text { alunos escutem o } \\
\text { professor e prejudica } \\
\text { a saúde do mesmo } \\
\text { por conta da } \\
\text { necessidade de falar } \\
\text { alto. }\end{array}$ \\
\hline $\begin{array}{l}\text { Conforto } \\
\text { hidrotérmico }\end{array}$ & $\begin{array}{l}\text { - As salas são muito quentes. } \\
\text { - Inexistência de ar condicionados e } \\
\text { os que existem estão sem funcionar. } \\
\text {-lluminação solar direta e intensa. }\end{array}$ & - & $\begin{array}{l}\text { - Influencia } \\
\text { diretamente no } \\
\text { desempenho e } \\
\text { concentração dos } \\
\text { alunos e professores. }\end{array}$ \\
\hline $\begin{array}{l}\text { Pureza e } \\
\text { qualidade } \\
\text { do ar }\end{array}$ & $\begin{array}{l}\text { - Os cheiros exalados durante o } \\
\text { preparo dos lanches e almoços } \\
\text { adentra as salas. }\end{array}$ & - & $\begin{array}{l}\text { - Tira a concentração } \\
\text { e atenção dos } \\
\text { alunos. }\end{array}$ \\
\hline Durabilidade & $\begin{array}{l}\text {-Falta de manutenção na pintura. } \\
\text { - Sanitários com defeitos } \\
\text { Quebrado. } \\
\text { - Mofo na sala dos professores e } \\
\text { biblioteca. }\end{array}$ & - & $\begin{array}{l}\text { - É importante } \\
\text { manter os ambientes } \\
\text { de ensino } \\
\text { aprendizagem } \\
\text { organizados, bonitos } \\
\text { e estimulantes. }\end{array}$ \\
\hline $\begin{array}{l}\text { Conforto } \\
\text { antropodinâ } \\
\text { mico }\end{array}$ & - & $\begin{array}{l}\text { - Verifica-se } \\
\text { uma } \\
\text { compatibilida } \\
\text { de com a } \\
\text { escala } \\
\text { humana. }\end{array}$ & $\begin{array}{l}\text { - É primordial que o } \\
\text { edifício seja } \\
\text { adequado as } \\
\text { práticas humanas } \\
\text { para qual o mesmo } \\
\text { foi desenvolvido. }\end{array}$ \\
\hline $\begin{array}{l}\text { Estanqueida } \\
\text { de }\end{array}$ & - & $\begin{array}{l}\text { Inexistência de } \\
\text { vazamentos } \\
\text { de água e } \\
\text { esgoto. }\end{array}$ & $\begin{array}{l}\text { - Necessário para a } \\
\text { manutenção da } \\
\text { saúde dos alunos, }\end{array}$ \\
\hline
\end{tabular}




\begin{tabular}{|c|c|c|c|}
\hline & & & $\begin{array}{l}\text { professores e } \\
\text { funcionários. }\end{array}$ \\
\hline Higiene & $\begin{array}{l}\text { - Os estrutura dos banheiros } \\
\text { dificultam a manutenção da } \\
\text { limpeza. }\end{array}$ & - & $\begin{array}{l}\text { - Necessário para a } \\
\text { manutenção da } \\
\text { saúde dos alunos, } \\
\text { professores e } \\
\text { funcionários. }\end{array}$ \\
\hline \multicolumn{4}{|c|}{ Requisitos quanto à manutenção NBR 5674} \\
\hline REQUISITO & DEFICIÊNCIA & CONFORMIDADE & $\begin{array}{l}\text { OBSERVAÇÕES E } \\
\text { DESCRIÇÓES DOS } \\
\text { USUÁRIOS }\end{array}$ \\
\hline $\begin{array}{l}\text { Sistemas } \\
\text { eletromecâni } \\
\text { cos }\end{array}$ & $\begin{array}{l}\text { - Inexistência de gerador de } \\
\text { energia elétrica. } \\
\text { - Falta de manutenção dos } \\
\text { aparelhos de ar condicionado. }\end{array}$ & - & $\begin{array}{l}\text { - A não existência de } \\
\text { geradores de } \\
\text { energia propicia a } \\
\text { não prática do } \\
\text { ensino aprendizagem } \\
\text { em situações de falta } \\
\text { de luz. } \\
\text { - A falta de ar } \\
\text { condicionado gera } \\
\text { desconforto no } \\
\text { ambiente. }\end{array}$ \\
\hline $\begin{array}{l}\text { Instalações } \\
\text { Hidráulico- } \\
\text { Prediais e } \\
\text { gás. }\end{array}$ & - & $\begin{array}{l}\text { - Sistema de } \\
\text { fossa, filtro e } \\
\text { sumidouro. } \\
\text { - } \\
\text { Abasteciment } \\
\text { o do gás de } \\
\text { cozinha por } \\
\text { botijão. }\end{array}$ & - \\
\hline Esquadrias & $\begin{array}{l}\text { - Esquadria em mau estado e } \\
\text { muitas sem vidro }\end{array}$ & - & $\begin{array}{l}\text { - As janelas sem vidro } \\
\text { e portas que não } \\
\text { fecham contribuem } \\
\text { para o desconforto } \\
\text { sonoro e térmico. }\end{array}$ \\
\hline $\begin{array}{l}\text { Sistemas } \\
\text { combate a } \\
\text { incêndios }\end{array}$ & -Somente extintores & - & $\begin{array}{l}\text { - A inexistência de } \\
\text { treinamento contra } \\
\text { incêndio tornam o } \\
\text { corpo docente e } \\
\text { discente } \\
\text { despreparado para } \\
\text { tal situação. }\end{array}$ \\
\hline $\begin{array}{l}\text { Revestimento } \\
\text { s de } \\
\text { Paredes, } \\
\text { pisos, tetos e } \\
\text { impermeabili } \\
\text { zação. }\end{array}$ & $\begin{array}{l}\text {-Piso das salas estão em maioria } \\
\text { quebrados. } \\
\text { - Telhado com defeitos. } \\
\text { - Falta de cobertura na quadra de } \\
\text { esportes. } \\
\text { - Infiltração na biblioteca e Sala dos } \\
\text { professores. } \\
\text { - Pinturas em mau estado de } \\
\text { conservação. }\end{array}$ & - & $\begin{array}{l}\text { - A falta de } \\
\text { manutenção } \\
\text { representa falta de } \\
\text { organização e torna } \\
\text { os ambientes } \\
\text { desestimulantes. }\end{array}$ \\
\hline Lazer & $\begin{array}{l}\text { Inexistência de lugares de lazer e } \\
\text { convívio. }\end{array}$ & - & $\begin{array}{l}\text { - O corpo docente e } \\
\text { discente não possui } \\
\text { lugares para } \\
\text { interagirem e } \\
\text { dialogarem durantes } \\
\text { os horários livres. }\end{array}$ \\
\hline
\end{tabular}




\begin{tabular}{|l|l|l|l|}
\hline Instalações & $\begin{array}{l}\text {-Instalações elétricas deficientes, } \\
\text { com fiação aparente. }\end{array}$ & $\begin{array}{l}\text { - Fiações aparentes } \\
\text { representam perigo a } \\
\text { saúde dos usuários. }\end{array}$ \\
\hline
\end{tabular}

Fonte: Elaborado pelas autoras

A análise técnica demonstrada acima expõe os principais focos de estudo necessários para execução de um projeto de arquitetura escolar. A partir da compreensão dos pontos negativos, positivos e das observações realizadas pelos usuários é possível assimilar e gerar discussões a respeito da arquitetura escolar. Tornar o usuário o ponto de partida em todo o processo de projeto é essencial, é verdadeiramente conceber arquitetura para humanos.

\subsection{Matriz de descobertas- diretrizes para projetos}

A matriz de descobertas é um mecanismo que torna possível identificar, comunicar e organizar graficamente as análises realizadas na durante a APO. Reuni e apresenta de maneira clara a síntese das descobertas fundamentais ocorridas durante a avalição de desempenho do ambiente construído (RHEINGANTZ et al., 2009).

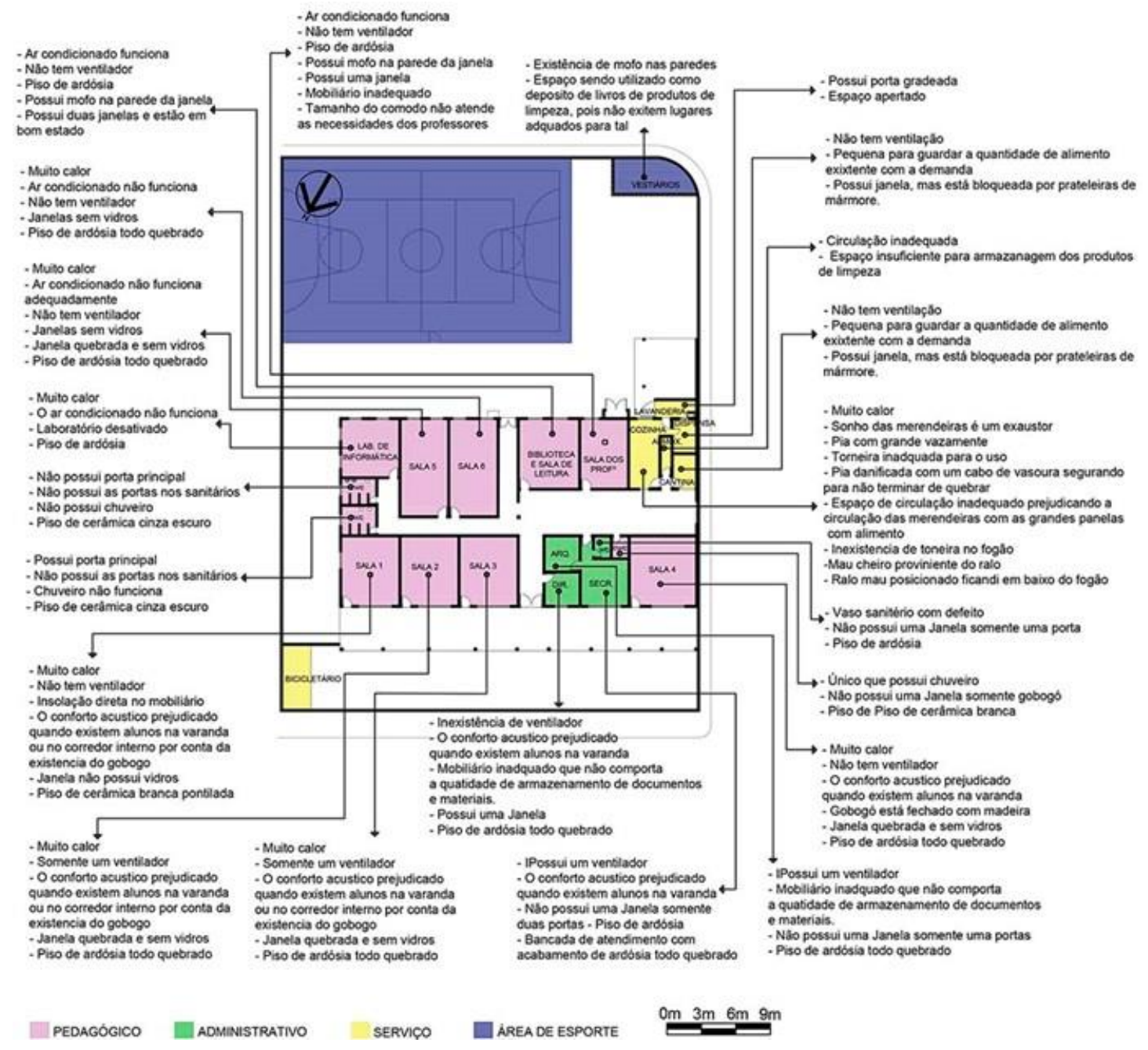

Figura 15 - Parte da Matriz de descobertas/ diretrizes de projeto-

Fonte: Elaborado pelas autoras (2018) 
Portanto, a síntese dos dados e informações do edifício educacional analisado nesta APO compõem um bando de dados que dão origem a diretrizes projetuais para futuros projetos de mesmo cunho arquitetônico. O objetivo desta pesquisa é estruturar instrumentos de projeto que se comportem como nortes no planejamento e execução de projetos de arquitetura escolar. O mapa de descobertas realizado pode ser observado na Figura 11.

\section{CONCLUSÕES}

Ao observar a realidade da escola, verifica-se que a proposta interacionista e objetivos descritos no PPP não estão materializados na arquitetura. Não existem respostas arquitetônicas para as necessidades dos usuários e para os objetivos do PPP. Todas as ferramentas aplicadas na APO demonstraram que o edifício da escola encontra-se em condições precárias. Sua estrutura não comporta a demanda por vagas na sala de aula, o que torna os ambientes superlotados.

A avaliação do conforto ambiental demonstra que este é outro ponto crítico na funcionalidade do edifício. As salas não possuem ventilação natural adequada o que as torna muito abafadas e quentes. Apenas duas salas possuem ar condicionado, porém um deles não funciona e o outro não é ligado por conta da falta de vidros na janela. Existem salas que não possuem ao menos um ventilador, o que torna o ambiente extremamente desconfortável prejudicando diretamente a prática do ensino- aprendizagem. As salas de aula voltadas para a fachada norte recebem calor excessivo tornando o interior das mesmas opressivo.

Como apresentado no mapa comportamental, as crianças não possuem lugares adequados para estarem durante os intervalos, o que dificulta a prática de esportes, brincadeiras assim como a sociabilização dos estudantes.

Deste modo, a presente APO, que é elaborada como um instrumento de análise do ambiente construído, possibilitou compreender na prática as demandas e necessidades de todos os grupos de usuários que compõem a equipe da Escola Municipal Luiza Terra de Andrade. Torna factível ainda, explorar a APO como um conjunto de diretrizes projetuais, podendo ser aplicada nos futuros projetos a serem desenvolvidos na respectiva escola ou em projetos arquitetônicos de mesma natureza e função.

\section{REFERÊNCIAS}

ANDRADE, Escola Municipal Luiza Terra de. Projeto Político Pedagógico Integração e Socialização: Escola- Comunidade. Arquivo interno da Escola Municipal Luiza Terra de Andrade. São Pedro da Aldeia RJ, 2016.

AZEVEDO, G. A. N. Arquitetura escolar e educação: um modelo conceitual de abordagem interacionista. 2002. Tese (doutorado em ciências em engenharia de produção) - Programas de pós-graduação de engenharia, Universidade federal do rio de janeiro, Rio de janeiro, 2002.

GRAÇA, V. A. C. Otimização de projetos arquitetônicos considerando parâmetros de conforto ambiental: o caso das escolas de rede Estadual de São Paulo. Campinas, SP, 2002. Dissertação (mestrado) - Faculdade de Engenharia Civil., Universidade Estadual de Campinas. 2002. 
IBGE. Gentílico: aldeiense, panorama. 2010. Disponível em: Instituto Brasileiro de Geografia e Estatística (IBGE). Cidades. Aldeiense, panorama. Acesso: 19/01/2019.

MOREIRA, L. G. S.; AZEVEDO, M. C. S. Atlas Escolar histórico e geográfico de São Pedro da Aldeia. Prefeitura de São Pedro da Aldeia. Rio de Janeiro: Grafline, 2012.

PREISER W. F. E.; RABINOWITZ H. Z.; WHITE E. T. Post-occupancy evaluation. NeW York: Van Nostrand Reinhold, 1988.

RHEINGANTZ, P. A.; AZEVEDO, G.; BRASILEIRO, A.; ALCANTARA, D.; QUEIROZ, M. Observando a Qualidade do Lugar: procedimentos para a avaliação pósocupação. Rio de Janeiro: FAU-UFRJ (Coleção PROARQ), 2009. Disponível em: <www.fau.ufrj.br/prolugar>. Acesso em: jan. 2019.

SANOFF, H. School Building Assessment Methods. Washington, DC: National Clearinghouse for Educational Facilities, 2001. Disponível em:

<http://www.ncef.org/pubs/sanoffassess.pdf>. Acesso em: 11 jan.19. 